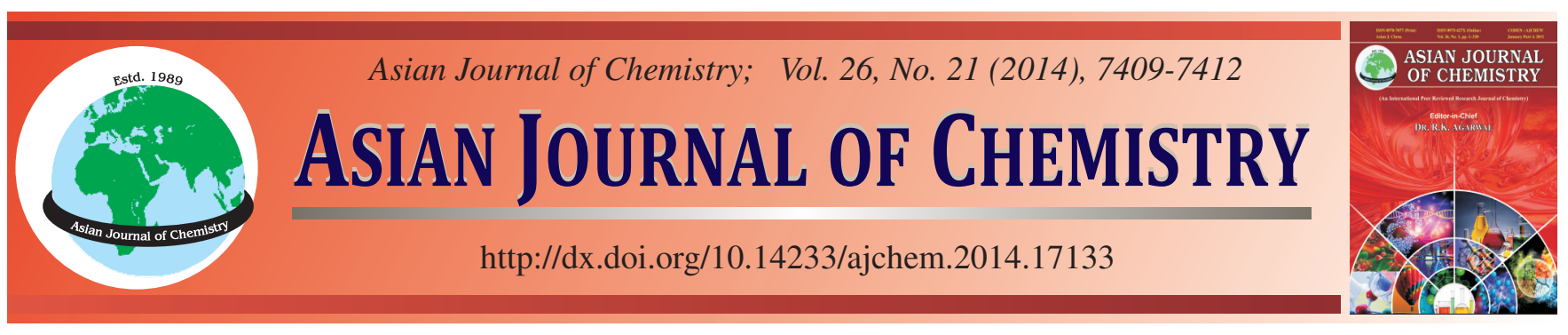

\title{
Removal of Cr(VI) from Aqueous Solution by Baritite Clay Adsorption
}

Ge Peng, Wangcai Liu*, Qiuping Li, Haojian Zhang and Hui Huang

School of Chemical Engineering, Ningbo University of Technology, Ningbo 315016, P.R. China

*Corresponding author: E-mail: wangcailiu@163.com

Received: 28 January 2014;

Accepted: 21 April 2014;

Published online: 30 September 2014;

AJC-16149

\begin{abstract}
Among the investigated clays and minerals (kaolinite, natural zeolite, manual zeolite, bentonite, sepiolite, sepiolite amianthus, tremolite amianthus, vermiculite and baritite), the baritite clay was selected as the optimal adsorbent for aqueous $\operatorname{Cr}(\mathrm{VI})$. The adsorption capacity of $\mathrm{Cr}(\mathrm{VI})$ on baritite clay reached as high as $39.01 \mathrm{mg} \mathrm{g}^{-1}$ at $20^{\circ} \mathrm{C}$. Then the adsorption kinetics and thermodynamics of $\mathrm{Cr}(\mathrm{VI})$ by the baritite clay were studied. Results showed that the pseudo-second-order model was a suitable description for the adsorption kinetics and fitted well with the experimental data. The calculated values of entropy $\left(\Delta \mathrm{S}^{\circ}\right)$ and enthalpy $\left(\Delta \mathrm{H}^{\circ}\right)$ changes of the adsorption process were $\Delta \mathrm{H}^{\circ}=-9.653 \mathrm{~kJ} / \mathrm{mol}$ and $\Delta \mathrm{S}^{\circ}=-22.57 \mathrm{~J} \mathrm{~mol}^{-1} \mathrm{~K}^{-1}$. This indicated that the adsorption of $\mathrm{Cr}(\mathrm{VI})$ on baritite clay was an exothermic process with chemical reactions. Finally, a hypothetical chemical adsorption mechanism of $\mathrm{Cr}(\mathrm{VI})$ was proposed.
\end{abstract}

Keywords: Chromate, Baritite clay, Adsorption, Kinetics, Thermodynamics.

\section{INTRODUCTION}

It is particularly important to maintain safe aquatic environments, where toxic metals are considerated to cause health problems to animals and human beings ${ }^{1}$. Removal of heavy metals is currently a matter of great concern. As the chromate is present in the effluents of electroplating, tanning, mining and fertilizer industries, the hexavalent chromium $\mathrm{Cr}(\mathrm{VI})$ pollution has become a major environmental problem. $\mathrm{Cr}(\mathrm{VI})$ is a strong mutagenic substance which can cause lung cancer and nasopharyngeal cancer ${ }^{2,3}$.

The harmful effects of $\mathrm{Cr}(\mathrm{VI})$ necessitate its removal from wastewater before release into streams. The removal of $\mathrm{Cr}(\mathrm{VI})$ has considerable ecological and economic interest and the selection of a removal method is based on the concentration of the metal ions, efficiency/cost ratio and adsorption capacity of the adsorbent ${ }^{4}$. Some strategies have been proposed for the removal of $\mathrm{Cr}(\mathrm{VI})$ from effluents, such as chemical precipitation, conventional coagulation, reverse osmosis ${ }^{5}$, ion exchange ${ }^{6}$ and adsorption on activated carbon ${ }^{7}$. However, most of these methods have some disadvantages such as complicated process, high cost and high energy consumption. Hence, there is a crucial need for the development of a method that is not only cost-effective and economic but can also be easily implemented. This leads to a search for low-cost, easily obtainable materials for the adsorption of heavy metals worldwide ${ }^{8-10}$.

So far, there was little report about the adsorption of aqueous $\mathrm{Cr}(\mathrm{VI})$ by the baritite clay. In this paper, it was found that the baritite clay is an efficient adsorbent for $\mathrm{Cr}(\mathrm{VI})$. As the baritite clay is low-cost and available with large quantity, applications of the baritite clay in the treatment of $\mathrm{Cr}(\mathrm{VI})$ wastewater have great promising prospects.

\section{EXPERIMENTAL}

The baritite clay, kaolinite, bentonite, sepiolite, sepiolite amianthus, natural zeolite, manual zeolite, tremolite amianthus and vermiculite were procured from Non-metallic Mining Co., Ltd of Jiacheng, Zhejiang in China. All the clays and minerals were screened at 80-100 mesh screens and calcined at $500{ }^{\circ} \mathrm{C}$ for $24 \mathrm{~h}$ before using them as adsorbents. Other compounds used in the adsorption process, such as $\mathrm{K}_{2} \mathrm{CrO}_{4}, \mathrm{BaSO}_{4}$, hydrochloric acid and deionized water, were supplied by Hangzhou Chemical Reagents Company (China).

Adsorption experiments: The adsorption experiments were carried out by using aqueous $\mathrm{Cr}(\mathrm{VI})$ solution, which was prepared by dissolving $\mathrm{K}_{2} \mathrm{CrO}_{4}$ in deionized water and the concentration of the stock solution is about $50 \mathrm{mg} \mathrm{Cr}(\mathrm{VI})$ per liter. Firstly, blank experiments were conducted without any clays or minerals on the similar conditions with the actual experiments, by taking $100 \mathrm{~mL}$ of $50 \mathrm{mg} / \mathrm{L} \mathrm{Cr}(\mathrm{VI})$ solutions in quartz flasks at $20{ }^{\circ} \mathrm{C}$ water bath and shaking the flasks in the frequency of $220 \mathrm{~Hz}$ for $1 \mathrm{~h}$. The results showed that there was not any measurable adsorption of $\mathrm{Cr}(\mathrm{VI})$ by the quartz flasks walls.

The adsorption of $\mathrm{Cr}(\mathrm{VI})$ by different clays and minerals were carried out in the same quartz flasks, by mixing together $0.1 \mathrm{~g}$ of adsorbent with $100 \mathrm{~mL}$ of $50 \mathrm{mg} / \mathrm{L} \mathrm{Cr}(\mathrm{VI})$ aqueous 
solution. The flasks were shaked gently at $20{ }^{\circ} \mathrm{C}$ water bath in the frequency of $220 \mathrm{~Hz}$ for $1 \mathrm{~h}$. Then the suspensions were centrifuged at 3,000 rpm for $10 \mathrm{~min}$. The $\mathrm{Cr}(\mathrm{VI})$ ions remaining unadsorbed in the supernatant were determined by atomic absorption spectrophotometer (Shimadzu, Spectr AA 6300 with air-acetylene oxidizing flame).

The adsorption experiments by kaolinite, natural zeolite, manual zeolite, bentonite, sepiolite, sepiolite amianthus, tremolite amianthus, baritite and vermiculite were carried out under the same initial conditions. At $20^{\circ} \mathrm{C}$ for $60 \mathrm{~min}$, each adsorbent is $0.1 \mathrm{~g}$ and the initial $\mathrm{Cr}(\mathrm{VI})$ ion concentration is $50 \mathrm{mg} / \mathrm{L}$. The results for different adsorbents are shown in Table- 1 .

Samples were run in duplicates and used as the curve dots. The amounts of $\mathrm{Cr}(\mathrm{VI})$ adsorbed were calculated by using the following formula:

$$
\mathrm{Q}_{\mathrm{t}}=\frac{\left(\mathrm{C}_{0}-\mathrm{C}_{\mathrm{t}}\right) \cdot \mathrm{V} / 1000}{\mathrm{~W}}
$$

where $\mathrm{Q}_{\mathrm{t}}\left(\mathrm{mg} \mathrm{g}^{-1}\right)$ is the adsorption capacity of $\mathrm{Cr}(\mathrm{VI})$ adsorbed on the baritite clay at time $t, \mathrm{C}_{0}\left(\mathrm{mg} \mathrm{L}^{-1}\right)$ is the initial $\mathrm{Cr}(\mathrm{VI})$ concentration, $\mathrm{C}_{\mathrm{t}}\left(\mathrm{mg} \mathrm{L}^{-1}\right)$ is the concentration of $\mathrm{Cr}(\mathrm{VI})$ in solution at time $t, \mathrm{~V}(\mathrm{~mL})$ is the volume of metal ion solution used and $\mathrm{W}(\mathrm{g})$ is the weight of the adsorbent used.

Furthermore, the adsorption of $\mathrm{Cr}(\mathrm{VI})$ by baritite clay was studied in details, including the adsorption kinetics and the temperature effects. Adsorption experiments data were shown in Fig. 1.

\section{RESULTS AND DISCUSSION}

Adsorption of $\mathrm{Cr}$ (VI) on various adsorbents: The result of $\mathrm{Cr}(\mathrm{VI})$ adsorption on various adsorbents was shown in Table-1. The considered adsorbents included baritite clay, kaolinite, bentonite, sepiolite, sepiolite amianthus, natural zeolite, manual zeolite, tremolite amianthus and vermiculite.

\begin{tabular}{lc}
\multicolumn{2}{c}{$\begin{array}{c}\text { TABLE-1 } \\
\text { Cr(VI) ADSORPTION USING DIFFERENT ADSORBENTS }\end{array}$} \\
\hline Adsorbents & Adsorption capacity $\left(\mathrm{mg} \mathrm{g}^{-1}\right)$ \\
\hline Natural zeolite & 29.62 \\
Manual zeolite & 31.79 \\
Sepiolite amianthus & 32.55 \\
Sepiolite & 30.78 \\
Bentonite & 26.93 \\
Kaolinite & 32.72 \\
Tremolite amianthus & 31.88 \\
Vermiculite & 26.94 \\
Baritite & 39.01 \\
\hline
\end{tabular}

As it was shown in Table-1, the baritite clay is the best adsorbent for $\mathrm{Cr}(\mathrm{VI})$ in aqueous solution among these studied adsorbents. The adsorption capacity of $\mathrm{Cr}(\mathrm{VI})$ reaches 39.01 $\mathrm{mg} \mathrm{g}^{-1}$, far more than other clays and minerals adsorbents. Therefore, the baritite clay was selected as the optimal adsorbent for $\mathrm{Cr}(\mathrm{VI})$, the adsorption of $\mathrm{Cr}(\mathrm{VI})$ in aqueous solution was investigated in present study.

Kinetics of $\mathrm{Cr}(\mathrm{VI})$ adsorption on the baritite clay: The results of the dynamic analysis usually were performed by the pseudo-first-order and pseudo-second-order rate equations. While Unuabonah et al. ${ }^{11}$ regarded pseudo-second-order kinetic as the proper expression for metal/sorbent sorption systems such as divalent metal ions using sphagnum moss peat ${ }^{12}$.

Therefore, the pseudo-second-order rate equation was used to study the adsorption kinetics of the adsorption of $\mathrm{Cr}$ (VI) by the baritite clay.

The pseudo-second-order model is represented by eqn. 2

$$
\frac{\mathrm{dQ}_{\mathrm{t}}}{\mathrm{dt}}=\mathrm{k}\left(\mathrm{Q}_{\mathrm{e}}-\mathrm{Q}_{\mathrm{t}}\right)^{2}
$$

The linear form of eqn. 2 can be written as follow eqn. 3

$$
\frac{\mathrm{t}}{\mathrm{Q}_{\mathrm{t}}}=\frac{1}{\mathrm{kQ}_{\mathrm{e}}^{2}}+\frac{\mathrm{t}}{\mathrm{Q}_{\mathrm{e}}}
$$

where $\mathrm{Q}_{\mathrm{t}}\left(\mathrm{mg} \mathrm{g}^{-1}\right)$ is the adsorption capacity of $\mathrm{Cr}(\mathrm{VI})$ adsorbed by the baritite clay at time $t, \mathrm{Q}_{\mathrm{e}}\left(\mathrm{mg} \mathrm{g}^{-1}\right)$ is the equilibrium adsorption capacity and $\mathrm{k}\left(\mathrm{g} \mathrm{mg}^{-1} \mathrm{~min}^{-1}\right)$ is the rate constant of pseudo-second-order model.

The initial sorption rate $\mathrm{h}\left(\mathrm{mg} \mathrm{g}^{-1} \mathrm{~min}^{-1}\right)$ was obtained according to eqn. 3, as $\mathrm{t} / \mathrm{Q}_{\mathrm{t}}$ approaches zero.

$$
\mathrm{h}=\mathrm{kQ}_{\mathrm{e}}{ }^{2}
$$

The amount $\mathrm{Cr}(\mathrm{IV})$ adsorbed data $v s$. time were shown in Fig. 1. According to the eqn. 3, the linear relation $t / \mathrm{Q}_{\mathrm{t}} \mathrm{t}$ of experimental data were also shown in Fig. 2.

According to the adsorption kinetics experiments data shown in Figs. 1 and 2, the parameters values of the eqn. 3 and 4 , such as the pseudo-second-order rate constant $\mathrm{k} \mathrm{g} \mathrm{mg}^{-1}$ $\left.\min ^{-1}\right)$, the initial sorption rate $\mathrm{h}\left(\mathrm{mg} \mathrm{g}^{-1} \mathrm{~min}^{-1}\right)$ and the equilibrium adsorption capacity $\mathrm{Q}_{\mathrm{e}}\left(\mathrm{mg} \mathrm{g}^{-1}\right)$ can obtained by linear regression. The results were shown in Table-2.

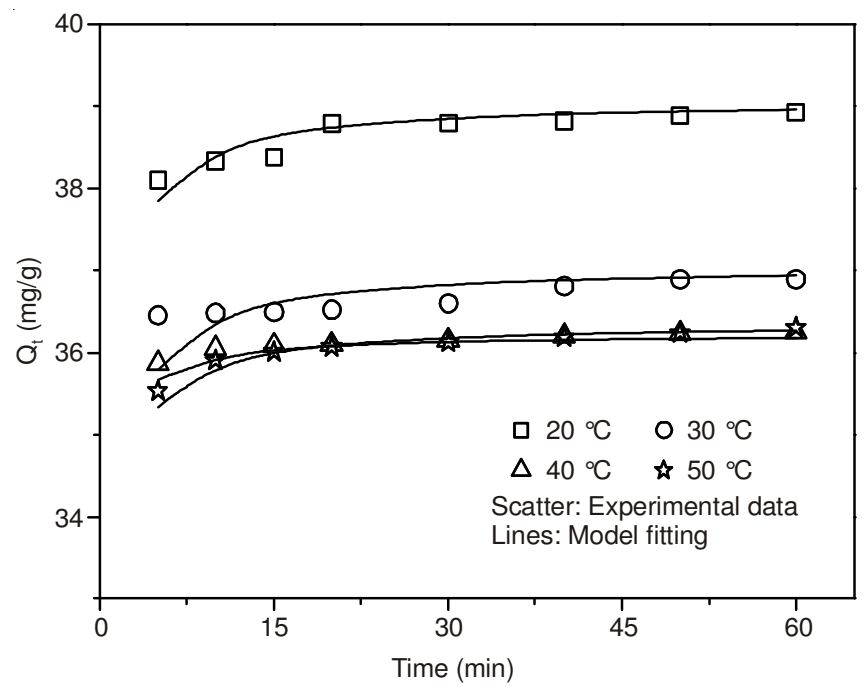

Fig. 1. Adsorption kinetics of $\mathrm{Cr}(\mathrm{VI})$ by baritite clay at different temperatures

\begin{tabular}{cccc}
\multicolumn{4}{c}{ TABLE-2 } \\
PARAMETERS OF THE ADSORPTION KINETICS \\
AT VARIOUS TEMPERATURE \\
\hline Temperature & $\begin{array}{c}\mathrm{Q}_{\mathrm{e}} \\
\left(\mathrm{mg} \mathrm{g}^{-1}\right)\end{array}$ & $\begin{array}{c}\mathrm{k} \\
\left(\mathrm{g} \mathrm{mg}^{-1} \mathrm{~min}^{-1}\right)\end{array}$ & $\begin{array}{c}\mathrm{h} \\
\left(\mathrm{mg} \mathrm{g}^{-1} \mathrm{~min}^{-1}\right)\end{array}$ \\
\hline 293.15 & 39.08 & 0.1596 & 243.7 \\
303.15 & 37.37 & 0.1523 & 212.6 \\
313.15 & 36.18 & 0.3470 & 454.2 \\
323.15 & 36.65 & 0.1967 & 240.3 \\
\hline
\end{tabular}




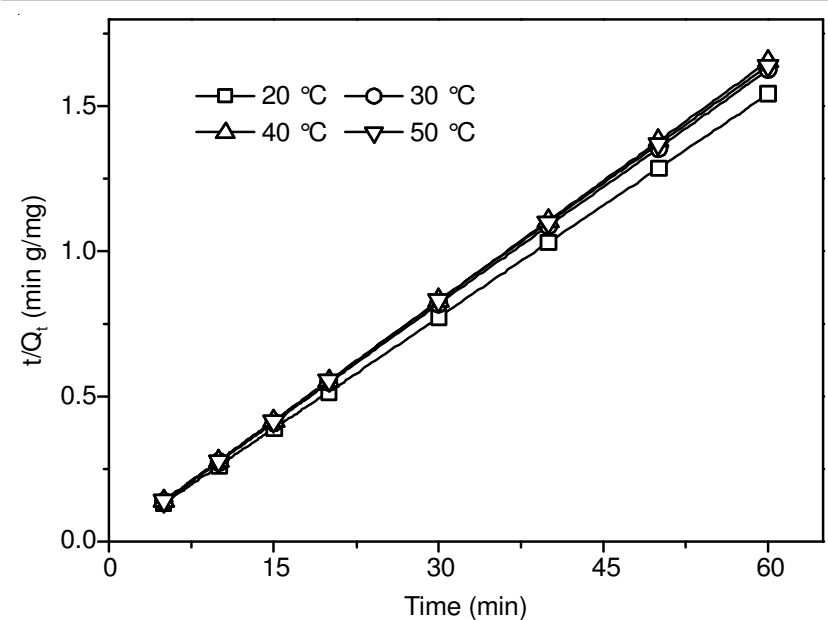

Fig. 2. Linear relation eqn. 3 describing the adsorption of $\mathrm{Cr}(\mathrm{VI})$

As the initial sorption rate $h$ is very fast (more than 200). It was shown that the linear correlation coefficient $\mathrm{R}^{2}$ at different temperature was about 1 . It indicated that the chemical reaction rather than physico-sorption is the main rate-controlling step throughout most of the adsorption process ${ }^{13}$.

The amount of $\mathrm{Cr}(\mathrm{VI})$ uptake, $\mathrm{Q}_{\mathrm{e}}\left(\mathrm{mg} \mathrm{g}^{-1}\right)$ was found to decrease from 39.08 to $36.65 \mathrm{mg} \mathrm{g}^{-1}$ when temperature increased from 20 to $50{ }^{\circ} \mathrm{C}$. This indicates that temperature has only a little effect on $\mathrm{Cr}(\mathrm{VI})$ adsorbed by baritite clay. The adsorption of $\mathrm{Cr}(\mathrm{VI})$ onto baritite clay was investigated in terms of the kinetics of adsorption mechanism by using pseudo-secondorder. Table- 1 showed that the increase in temperatures in the range of 20 to $40^{\circ} \mathrm{C}$ resulted in the increase of the rate constant, $\mathrm{k}$, from 0.1596 to $0.3470 \mathrm{~g} / \mathrm{mg} \mathrm{min}^{-1}$. However, when the temperature increased to $50^{\circ} \mathrm{C}$, the rate constant $(\mathrm{k})$ decreased to $0.1967 \mathrm{~g} / \mathrm{mg} \mathrm{min}^{-1}$. In addition, the initial sorption rate $(\mathrm{h})$ also increased from 243.7 to $454.2 \mathrm{mg} / \mathrm{g} \mathrm{min}^{-1}$ and the initial sorption rate (h) decreased to $240.3 \mathrm{mg} \mathrm{g}^{-1} \mathrm{~min}^{-1}$ when it was $50{ }^{\circ} \mathrm{C}$. The results of the rate constant $(\mathrm{k})$ and initial sorption rate $(\mathrm{h})$ indicated that it's adverse for $\mathrm{Cr}(\mathrm{VI})$ adsorbed at higher or lower temperature in the range of 20 to $50{ }^{\circ} \mathrm{C}$. Increase in temperature causes increase in the mobility of the ions. If temperature is further increased, the kinetic energies of chromium ions become higher than the potential attractive forces between active sites and ions ${ }^{14}$. The results described above may be explained as a result of this phenomenon.

Thermodynamics of $\mathbf{C r}(\mathrm{VI})$ adsorption: When the adsorption equilibrium of the $\mathrm{Cr}(\mathrm{VI})$ on the baritite clay is established, the adsorbed $\mathrm{Cr}(\mathrm{VI})$ is in equilibrium with the residual $\mathrm{Cr}(\mathrm{VI})$ concentration ${ }^{15,16}$. The values of equilibrium constant $\left(\mathrm{K}_{\mathrm{d}}\right)$ of the adsorption process at different temperatures could be calculated from eqn. 5 .

$$
\mathrm{v}-\frac{\mathrm{Q}_{\mathrm{e}} \mathrm{m}}{\mathrm{C}_{\mathrm{e}} \mathrm{V}}
$$

Which $\mathrm{Q}_{\mathrm{e}}\left(\mathrm{mg} \mathrm{g}^{-1}\right)$ is the equilibrium adsorption capacity, $\mathrm{C}_{\mathrm{e}}\left(\mathrm{mg} \mathrm{L}^{-1}\right)$ is the $\mathrm{Cr}(\mathrm{IV})$ concentration remaining in solution at equilibrium, $\mathrm{m}(\mathrm{g})$ is the mass of the adsorbent and $\mathrm{V}(\mathrm{L})$ is the volume of solution.

The standard Gibbs free energy $\left(\Delta \mathrm{G}^{\circ}\right)$ of the adsorption process could be calculated from eqn. 6

$$
\Delta \mathrm{G}^{\circ}=-\mathrm{RT} \ln \mathrm{K}_{\mathrm{d}}
$$

where $\mathrm{R}\left(8.3145 \mathrm{~J} \mathrm{~mol}^{-1} \mathrm{~K}^{-1}\right)$ is the ideal gas constant and $\mathrm{T}$ $(\mathrm{K})$ is the temperature.

According to the van't Hoff equation eqn. 7, The values of entropy $\left(\Delta \mathrm{S}^{\circ}\right)$ and enthalpy $\left(\Delta \mathrm{H}^{\circ}\right)$ changes of the adsorption process can also by calculated by plotting of $\ln \mathrm{K}_{\mathrm{d}}$ versus $1 / \mathrm{T}$.

$$
\ln \mathrm{K}_{\mathrm{d}}=\frac{\Delta \mathrm{S}^{\circ}}{\mathrm{R}}-\left(\frac{\Delta \mathrm{H}^{\circ}}{\mathrm{R}}\right) \frac{1}{\mathrm{~T}}
$$

The plots of $\ln \mathrm{K}_{d}$ versus $1 / \mathrm{T}$ were shown in Fig. 3. The linear data fitting was satisfactory with of the linear relation coefficient $\mathrm{R}^{2}=0.9528$. The calculated values of $\Delta \mathrm{H}^{\circ}$ and $\Delta \mathrm{S}^{\circ}$ of the adsorption of $\mathrm{Cr}(\mathrm{VI})$ on the Baritite clay and the experimental $\mathrm{K}_{\mathrm{d}}$ data were all listed in Table-3.

\begin{tabular}{ccccc}
\multicolumn{5}{c}{ TABLE-3 } \\
THERMODYNAMIC PARAMETERS FOR \\
\multicolumn{4}{c}{ THE ADSORPTION OF Cr(VI) ON THE BARITITE CLAY } \\
\hline $\begin{array}{c}\text { Temperature } \\
(\mathrm{K})\end{array}$ & $\mathrm{K}_{\mathrm{d}}$ & $\begin{array}{c}\Delta \mathrm{G}^{\circ} \\
\left(\mathrm{kJ} \mathrm{mol}^{-1}\right)\end{array}$ & $\begin{array}{c}\Delta \mathrm{H}^{\circ} \\
\left(\mathrm{kJ} \mathrm{mol}^{-1}\right)\end{array}$ & $\begin{array}{c}\Delta \mathrm{S}^{\circ} \\
\left(\mathrm{J} \mathrm{mol}^{-1} \mathrm{~K}^{-1}\right)\end{array}$ \\
\hline 293.15 & 3.579 & -3.109 & -9.653 & -22.57 \\
303.15 & 2.959 & -2.735 & & \\
313.15 & 2.618 & -2.507 & & \\
323.15 & 2.484 & -2.446 & & \\
\hline
\end{tabular}

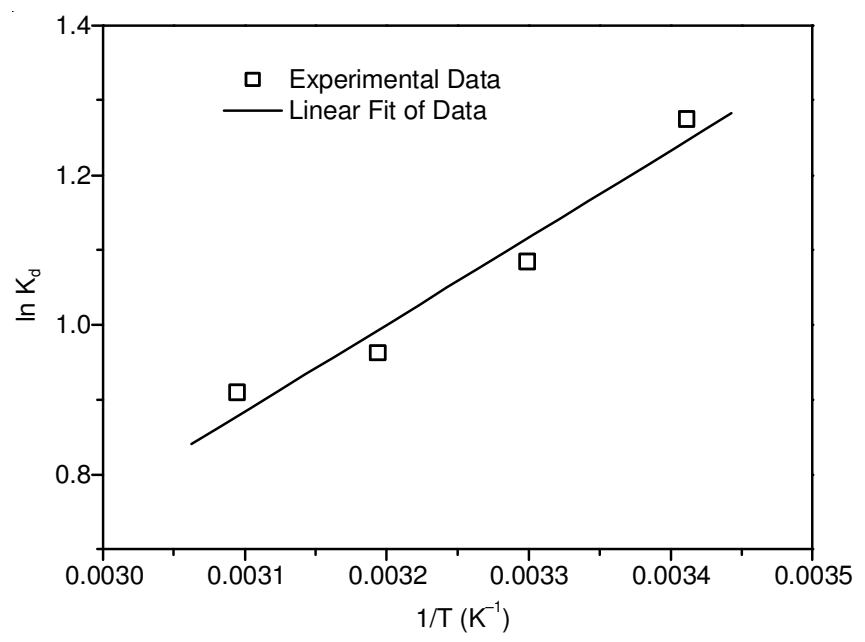

Fig. 3. Plot of $\ln \mathrm{K}_{\mathrm{d}}$ versus $1 / \mathrm{T}$ for the adsorption of $\mathrm{Cr}(\mathrm{VI})$ on the baritite clay

As it was shown in Table-3, the negative value of enthalpy change $\left(\Delta \mathrm{H}^{\circ}\right)-9.653 \mathrm{~kJ} \mathrm{~mol}^{-1}$ indicated that the adsorption of $\mathrm{Cr}(\mathrm{VI})$ was exothermic process with chemical reactions. The negative entropy change $\left(\Delta \mathrm{S}^{\circ}\right)$ values $-22.57 \mathrm{~J} \mathrm{~mol}^{-1} \mathrm{~K}^{-1}$ revealed that the orderliness of the adsorbed system was higher than the solution phased before adsorption. The Gibbs free energy $\Delta \mathrm{G}^{\circ}$, listed in Table-3, as calculated for adsorption of $\mathrm{Cr}(\mathrm{VI})$ on baritite clay were $-3.109,-2.735,-2.507$ and -2.446 $\mathrm{kJ} \mathrm{mol}^{-1}$ when the temperature was set at 293.15, 303.15, 313.15 and $323.15 \mathrm{~K}$. It suggested that the adsorption process of $\mathrm{Cr}(\mathrm{VI})$ on the baritite clay was feasible and spontaneous thermodynamical. Furthermore, the Gibbs energy increase with increasing temperature suggested that the adsorption of $\mathrm{Cr}(\mathrm{VI})$ on the baritite clay was less favorable at higher temperatures.

Mechanism of $\mathrm{Cr}(\mathrm{VI})$ adsorption on baritite clay: The main ingredient of baritite clay is barium sulfate $\mathrm{BaSO}_{4}$, which can form in dissolvable dichromates from the aqueous solution of $\mathrm{Cr}(\mathrm{VI})$. Then the in dissolvable chromates such as $\mathrm{BaCr}_{2} \mathrm{O}_{7}$ 
and $\mathrm{Ba}\left(\mathrm{HCr}_{2} \mathrm{O}_{7}\right)_{2}$ adsorbed on the clay with $\mathrm{Cr}_{2} \mathrm{O}_{7}^{2-}$ and $\mathrm{HCr}_{2} \mathrm{O}_{7}^{-}$ to remove $\mathrm{Cr}(\mathrm{VI})$. The process of adsorption on the baritite clay surface sites are formulated as following expressions:

$$
\begin{aligned}
& \mathrm{BaSO}_{4}+\mathrm{Cr}_{2} \mathrm{O}_{7}{ }^{2-} \leftrightarrow \mathrm{BaCr}_{2} \mathrm{O}_{7}+\mathrm{SO}_{4}{ }^{2-} \\
& \mathrm{BaSO}_{4}+2 \mathrm{HCr}_{2} \mathrm{O}_{7}{ }^{-} \leftrightarrow \mathrm{Ba}\left(\mathrm{HCr}_{2} \mathrm{O}_{7}\right)_{2}+\mathrm{SO}_{4}{ }^{2-}
\end{aligned}
$$

The formation of $\mathrm{BaCr}_{2} \mathrm{O}_{7}$ and $\mathrm{Ba}\left(\mathrm{HCr}_{2} \mathrm{O}_{7}\right)_{2}$ complexes can explain the higher adsorption capacity of baritite for Cr(VI).

\section{Conclusion}

The results obtained from baritite clay used for removal of $\mathrm{Cr}(\mathrm{VI})$ from aqueous solution demonstrated that baritite clay is a feasible alternative for the chemical and physical adsorption of $\mathrm{Cr}(\mathrm{VI})$. In addition, the adsorption of $\mathrm{Cr}(\mathrm{VI})$ by baritite clay followed the linearity of the plots of the pseudosecond-order model well. Furthermore, The negative value of enthalpy change, $\Delta \mathrm{H}^{\circ}$ and Gibbs free energy change, $\Delta \mathrm{G}^{\circ}$, indicated that the adsorption of $\mathrm{Cr}(\mathrm{VI})$ on baritite clay was a feasible, spontaneous thermodynamically and exothermic process. Thus, baritite clay is a meaningful material used to remove heavy mental like $\mathrm{Cr}(\mathrm{VI})$, it makes sense to research further.

\section{REFERENCES}

1. M. Minamisawa, H. Minamisawa, S. Yoshida and N. Takai, J. Agric. Food Chem., 52, 5606 (2004).

2. T.S. Anirudhan, S.P. Jalajamony and S. Suchithra, Eng. Asp., 335, 107 (2009).

3. R.L. Goswamee, P. Sengupta, K.G. Bhattacharyya and D.K. Dutta, Appl. Clay Sci., 13, 21 (1998).

4. K.O. Adebowale, I.E. Unuabonah and B.I. Olu-Owolabi, J. Hazard. Mater., 134, 130 (2006).

5. I.D. Atamanenko, A.P. Kryvoruchko, L.Y. Yurlova and B.Y. Kornilovich, Desalination, 158, 151 (2003).

6. I.H. Lee, Y.C. Kuan and J. Chern, J. Hazard. Mater., 138, 549 (2006).

7. S. Babel, J. Hazard. Mater., B97, 219 (2003).

8. K. Kadirvelu, K. Thamaraiselvi and C. Namasivayam, Bioresour. Technol., 76, 63 (2001).

9. K. Kadirvelu, P. Senthilkumar, K. Thamaraiselvi and V. Subburam, Bioresour. Technol., 81, 87 (2002).

10. W.C. Leung, M.F. Wong, W.H. Chua, P.H.F. Lo and C.K.Y. Leung, Water Sci. Technol., 41, 233 (2000).

11. E.I. Unuabonah, K.O. Adebowale and B.I. Olu-Owolabi, J. Hazard. Mater., 144, 386 (2007).

12. A.P. Carnizello, L. Marcal, P.S. Calefi, E.J. Nassar, K.J. Ciuffi, R. Trujillano, M.A. Vicente, S.A. Korili and A. Gil, J. Chem. Eng. Data, 54, 241 (2009).

13. M.Q. Jiang, Q.P. Wang, X.Y. Jin and Z.L. Chen, J. Hazard. Mater., 170, 332 (2009).

14. M. Uysal and I. Ar, J. Hazard. Mater., 149, 482 (2007).

15. A.A. Atia, Appl. Clay Sci., 41, 73 (2008).

16. G. Peng, L.J. Wan and L.X. Wang, Asian J. Chem., 24, 3457 (2012). 